\title{
Steven Laporte
}

Vrije Universiteit Brussel (Belgium)

steven.laporte@vvub.ac.be

\section{Preprint for the humanities - fiction or a real possibility?*}

\begin{abstract}
Even though the use of open preprint databases for scholarly publications is commonplace in several disciplines, their possibilities remain largely unexplored in the humanities. This article examines the emergence and the dynamics of academic preprint and evaluates the possibilities for introducing preprint for the humanities.
\end{abstract}

Keywords: preprint, arXiv, academic publishing, bibliometrics, library science, bumanities.

* A preprint of this article you can find at SocArXiv (January 16, 2017). Available online: http://osf.io/preprints/socarxiv/jebhy/.

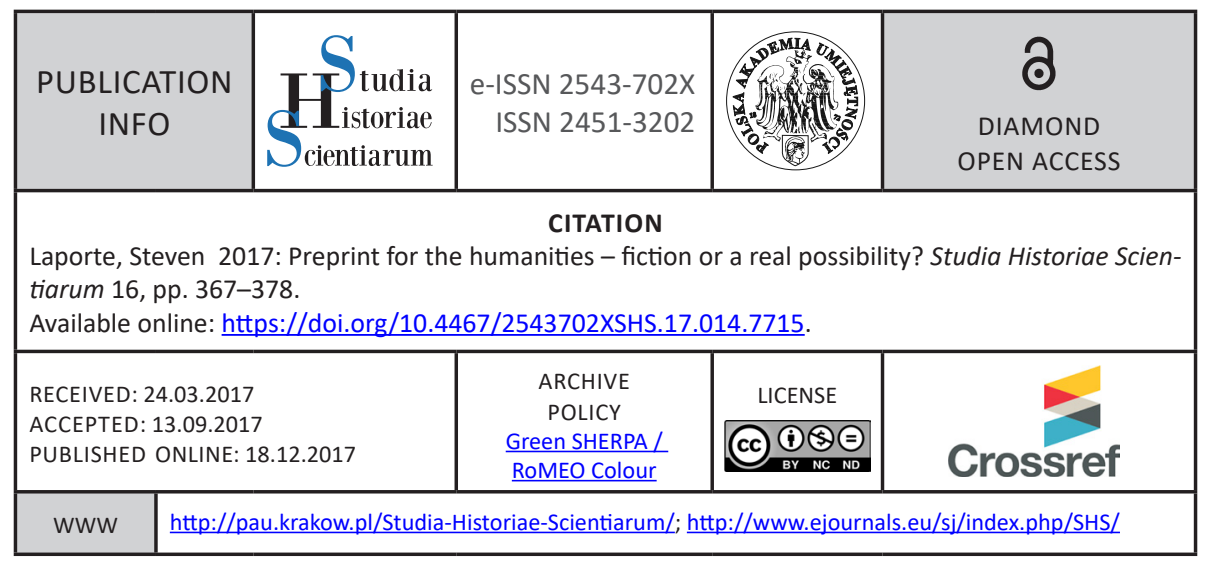




\title{
Preprint w humanistyce - fikcja czy realna możliwość?
}

\begin{abstract}
Abstrakt
Pomimo że korzystanie z otwartych baz preprintów publikacji naukowych jest powszechne w wielu dyscyplinach, możliwości takich baz preprintów pozostają w dużej mierze niewykorzystane w naukach humanistycznych. Artykuł omawia powstawanie i dynamikę preprintu akademickiego oraz ocenia możliwości wprowadzenia preprintów w naukach humanistycznych.
\end{abstract}

Słowa kluczowe: preprint, arXiv, publikacje naukowe, bibliometria, bibliotekoznawstwo, bumanistyka.

\section{The two publication cultures}

There is little point in denying it: The humanities have never felt completely at ease with the way in which scientific output is measured through bibliometrics ${ }^{1}$. So why do researchers in the humanities cling to the structures that are linked with the traditional use of bibliometric methods so fiercely?

When comparing the differences in publication culture that exist between various fields, the humanities display a very conservative attitude. Scholarly papers that are written in the humanities only really come into intellectual existence after they are published in a peer reviewed journal. In the time between the first submission of a paper and its final publication - usually several months later - the work remains dormant in the sense that there exists very little interaction with the scientific community about the content, apart from the interaction with the reviewers themselves. Before the first submission of the paper, interaction with the community is often limited to an inner circle of immediate collaborators. The publication of monographs follows a similar path.

${ }^{1}$ Many publications have confronted the problems of research evaluation in the humanities. The issues involved are typically included in textbooks for citation analysis, e.g. Moed 2005. Numerous proposals have been forwarded to resolve the situation e.g. Linmans 2010. For a good overview I recommend reading the excellent article by Thed van Leeuwen (2013), but there are many, many more. 
If this seems like the only proper way to go about the business of scholarly publishing, think again. The most notable example of a completely different approach in supplying academic findings to the rest of the scientific community originated in the field of physics, more precisely in the subfield of high energy physics (HEP). In high energy physics papers are generally submitted to an academic journal only after the phase of intense academic debate is concluded. ${ }^{2}$ Formal publication is actually not very interesting to the active scholars in the field, and mainly serves a filing function and credit gathering function. The published articles are basically meant to assure outsiders that a piece of work has significance when decisions have to be made about appointments, promotions and funding. ${ }^{3}$

But if not through formal publication, then how do high energy particle physicists share their work? The answer to that question is preprint. By preprint we mean the circulation of papers amongst scholars before the work is even submitted to a scientific journal. ${ }^{4}$ The tool that is predominantly used today is a large preprint database called arXiv. ${ }^{5}$ To better understand the supply of academic information in a different field like philosophy, it will prove useful to first explore this example in more detail.

\section{2. $a r X i v$}

ArXiv started in 1991 at Los Alamos National Laboratories and is now based at Cornell University. It is operated by a limited number of people and funded entirely through grants. It contains $99 \%$ of all written research output in HEP. ${ }^{6}$ At its conception it was merely an email based reflection of an existing practice amongst practitioners of HEP. This practice went as follows: whenever researchers had something to communicate to their peers they would deposit a written copy of the research at the university library. An inventory of the papers that were available in the library was made public on a bulletin board near the

\footnotetext{
${ }^{2}$ Delfanti 2016.

${ }^{3}$ Bohlin 2004.

${ }^{4}$ Gunnarsdottir 2005.

${ }^{5}$ Cf. http://arxiv.org.

${ }^{6}$ Delfanti 2016.
} 
entrance of the library, or by means of a simple card system. Any interested colleague could ask for a copy of the original paper for private use. In this way research information in a rapidly advancing field could travel easily between all interested scholars. By the 1960's a true preprint culture had already matured amongst physicists. The size of the repository of preprints added to the prestige of the university library. Soon however, universities started sharing preprint information. In the 1980's a bibliographic database was created by the combined efforts of institutions on both sides of the Atlantic ${ }^{7}$ which formed the basis for a global preprint exchange culture.

ArXiv encapsulated this principle in a much more global and practical way by bringing the platform to the web, basically setting up a parallel structure next to basic peer reviewed publishing. The platform is totally open access with no cost for the reader or the contributor. ${ }^{8}$ To submit a paper to the archive (as it is colloquially called amongst physicists) it must be sent from 1) a recognized institutional email account. A new user must also be 2) endorsed by a recognized user 3) screening for plagiarism is done automatically and followed by 4) human moderation. ${ }^{9}$

Publishing papers on arXiv is a way for active physicists to build a reputation. This may seem counter-intuitive to some, because it is often thought that preprint is a gateway to plagiarism of work that not yet enjoys the protection of registered publications.

But in HEP a lot of research - for example in the large hadron collider at CERN - is a collaborative effort with tens or even hundreds of scientific contributors, so it is not always easy for an individual to stand out. Through individual contributions to arXiv they can reclaim their individuality. Because of the very short time it takes for an article to get published ${ }^{10}$ new findings reach their audiences extremely fast. Because

${ }^{7}$ For a detailed overview of the development of arXiv and its precursors see Gunnarsdottir $\underline{2005}$.

${ }^{8}$ In the slipstream of the emergence of a digital preprint culture a typesetting tool was developed called TeX and later LaTeX. This free software that is still widely in use, allows the individual researcher to produce state of the art layouts for articles without the aid of a professional publisher.

${ }^{9}$ Reyes-Galindo 2016.

${ }^{10}$ All articles submitted before 4.00 pm EST are published every weekday at $8.00 \mathrm{pm}$. 
of the high standard, in-crowd nature of the users of $a r X i v$, it operates also as a kind of pre-peer review for the official publishers. This explains the very high acceptance rating of articles published in journals like Physical Review Letters and Journal of High Energy Physics. And last but not least, all dependence on publisher paywalls or even the spatio-temporal limitation of using the university library ceases to exist.

\section{Preprint in other fields}

After unwrapping this example, one question presents itself: Why does a similar publication culture not exist for the humanities in general or for philosophy in particular? Just consider the advantages: 1) no paywalls, 2) speed of publication, 3) a global reach, 4) an intense debating culture, 5) peripheralization of bibliometric, financial and managerial tomfoolery. The preprint culture arguably manages to keep the focus firmly on the research and away from external influences. So it is no surprise that a number of other disciplines have embraced the arXiv model. Mathematics being the first to adopt its principles, followed by computer science, statistics, quantitative biology and quantitative finance. In 2013 biorXiv ${ }^{11}$ was founded as an arXiv inspired platform, for the life sciences and it is likely that we will soon see the introduction of Soc ArXiv ${ }^{12}$ for the social sciences. ${ }^{13}$

A number of reasons can be given for this late- (or non-) adoption of the technology and its principles by other disciplines. One of them is money. Publications in arXiv are typically of a very theoretical nature, which means that they are a long way from being able to be converted into profitable patents for industry to capitalize on. This is why disciplines like chemistry and pharmaceutical sciences tend to be much more reluctant to publicly disseminate their findings.

But surely a field like philosophy does not suffer the shame of being overly practical? Nor can it be claimed that by adhering to a highly loose publication culture its practitioners might miss out on huge potential financial gain? So what is stopping them?

\footnotetext{
${ }^{11}$ Cf. http://www.biorxiv.org.

${ }^{12}$ Cf. https://osf.io/preprints/socarxiv.

${ }^{13}$ Cohen 2016.
} 


\section{Steven Laporte}

To answer this question we have to look into the publication culture that is dominant in the humanities. To do this we should move beyond the heterogeneous collection of disciplines gathered under the label of the humanities. ${ }^{14}$ For practical reasons we will limit the discussion to the field of philosophy, although most of the arguments are applicable to other fields within the humanities as well.

First let us consider the question of language. It is a simple fact that English has firmly established itself as the lingua franca for science. This brought about many advantages for the development of a global scientific community. By wilfully adopting English as the standard language for communication, researchers can potentially reach out to anyone working on a subject of interest, on a global scale. But English is not the only language used in philosophy. Far from it, and there are very good reasons for this. For instance, it is often impossible to remove a historical aspect of the subject matter when dealing with philosophy: Valuable works from the seventeenth century A.D. or indeed from the fifth century B.C. - when English did not yet develop, or had not yet reached its current status - must remain in their original form in order to retain their proper value. In this context, translation inevitably means the loss of a significant part of the content.

The multitude of languages that are used in philosophy will remain a factor that complicates matters. Pockets of valuable knowledge will remain inaccessible for those who do not master the language they are written in. But on the other hand, what is stopping us from indexing them and making them readily available for all who want to consult them, nevertheless?

Secondly we may consider the nonlinear nature of philosophical discourse. At the risk of oversimplifying matters we may see research in HEP as a quest with a more or less singular answer that can settle the matter, once it is discovered. Of course we know this not to be entirely true, but it can be argued that in physics the tendency towards the layering of levels of interpretation is not as strong as it is in philosophy. Yet in mathematics for example - a field that also uses arXiv and preprint intensively - the degree of specialisation into various sub-fields is notoriously very high. This high degree of specialisation produces

\footnotetext{
${ }^{14}$ Hammarfelt 2014.
} 
problems of a similar nature. A paper that is written as part of a solution to a particular subproblem does not necessarily mobilize the entire research community. It suffices to alert just the right people to get the right kind of feedback from the community. In the same way the problem of layering could be addressed. Again the key lies in clever indexing.

Thirdly there are monographs. These are a rare commodity in HEP and when they do see daylight they are generally not targeted at the research community itself, but rather at interested outsiders and students. Not so in philosophy. Monographs are - even more so than journal articles - the lifeblood of philosophy. And they cannot be made free-for-all without there being there being serious (financial) consequences for the authors and their publishers. The preparation of a scientific book demands a serious investment from the publisher, whereas a peer reviewed journal article is edited to a large extend by the appointed reviewers themselves. The main cost for the publisher of a digital academic database is the development and the maintenance of the platform where the work is deposited. The publication of an article in a traditional journal or a monograph is far more labour intensive. Although some authors have resorted to publishing their books in an open access format - and thus relinquishing a possible financial remuneration for their labour - this cannot be expected to be a viable alternative for all in the foreseeable future. But maybe we should not think of monographs as the engine, but rather as the product and the catalyst of intellectual debate? This would possibly even disqualify them from the preprint model. In a way this would put monographs in the humanities on the same level as postprint articles and textbooks in HEP, namely that of tested and approved.

Next we may consider articles written for popular magazines and newspapers. It may rightfully be expected of a professional philosopher to act as a public intellectual, and doing so often involves delivering articles to the popular press. These articles are generally not considered scholarly papers, but are they outside the academic canon altogether? This is debatable. It is evidently so that a popular article is not peer reviewed in the formal sense, but this doesn't mean that it is not seen by the peers of the author. It is certainly not gratuitous and often becomes part of the intellectual debate inside academic circles as well as in the public sphere. Popular press in physics has an altogether different dynamic. Here the article is usually aimed at explaining difficult theoretical 
concepts or research findings to the layman. It is tantalising to consider integrating popular articles by philosophers when indexing the academic production of the field, and preprint may be a way to facilitate this.

Five is the grip that large academic publishing houses have on scientific publishing. In an extensive article that was published in 2015 entitled "The Oligopoly of Academic Publishers in the Digital Era", 15 it is convincingly shown how a few large publishers over the past decades, have managed to secure excessive profit margins. This is made possible because of the widespread conviction that publishing houses play a central role in the organisation and dissemination of scientific knowledge. Preprint culture clearly demonstrates that this is not the case. At the start of the digital preprint tradition in physics, mathematics and computer science, scientists actively discarded any copyright objections publishers would want to make by simply crossing out in their contracts the clauses that prohibit publication of the work elsewhere. Researchers in the humanities (and other disciplines) up to this day have not made a similar stance and consequently remain under the effective control of their publishers.

The sixth consideration is about skill and familiarity with digital applications. Considering arXiv started in 1991, it is safe to say that physicists are early adaptors of the new digital technology. Where users in the humanities turn to digital platforms in the capacity as clients, physicists and computer scientists build themselves the platforms they need.

\section{The alternatives}

This brings us to the current situation. Because on the supply side of academic information in philosophy, things are slowly beginning to change. Yet again it is by outside initiatives, rather than by forces mustered from within the community. Pre-publishing for example is slowly becoming a thing for the humanities, but the way it is currently coming about is diffuse. A number of possibilities are already available to the general public and researchers alike to disseminate texts: personal websites can be used to make content available. Institutional repositories collect and distribute the work of their members.

\footnotetext{
${ }^{15}$ Larivière, Haustein, Mongeon 2015.
} 
In addition to this we saw the rise - in recent years - of initiatives like Academia $^{16}$ and Researchgate ${ }^{17}$. Both are privately funded, digital platforms that provide individual researchers the possibility to form networks with colleagues all over the globe through sharing research findings and issuing early (or past) publications.

Academia was founded in 2008 by Richard Price a ... philosopher(!) who had the idea while working on his $\mathrm{PhD}$ at the university of $\mathrm{Ox}-$ ford. It operates with an invested capital of $\$ 17.7$ million dollar by a variety of funders (Khosla Ventures, True Ventures, Spark Ventures, Spark Capital and Rupert PennantReam).

Researchgate was also founded in 2008 by virologist and computer scientist Dr. Ijad Madisch, Dr. Sören Hofmayer (another physician) and computer scientist Horst Fickenscher. Among its investors we find Microsoft founder Bill Gates.

A third major player in the emergence of new social platforms for sharing scholarly information is the content manager Mendeley ${ }^{18}$, providing social networking services as well as publication possibilities. Mendeley started out independently but was bought in 2013 by the Elsevier corporation.

But what all of these platforms seem to be missing is one crucial thing: unity. Where arXiv unites all pre-publications in a specific field, the previous platforms divide the humanities up amongst them. This results in a situation where there is only limited recognition from the community about the authorship of preprints. It is therefore a hazardous enterprise for a researcher to put research out there, where someone else can just steal the idea and publish it for real elsewhere. But the emergence of institutional repositories may provide an answer to this problem.

For philosophy there exists another initiative that tries - and to a large extend succeeds - to index all publications in the field under one flag and that is PbilPapers ${ }^{19}$. It is a mainly grant-driven initiative that is maintained by the Centre for Digital Philosophy at the University of Western Ontario (Canada). Other initiatives that are worth mentioning

\footnotetext{
${ }^{16}$ Cf. https://www.academia.edu.

${ }^{17}$ Cf. https://www.researchgate.net.

${ }_{18}$ Cf. https://www.mendeley.com.

${ }^{19}$ Cf. https://philpapers.org.
} 
are the International Directory of Pbilosophy ${ }^{20}$ that is maintained by the Philosophy Documentation Center.

But none provide the key strong points of the arXiv framework: free full-text access to articles combined with a centralised and independent repository and a broad recognition amongst serious practitioners.

\section{Conclusion}

In conclusion of this article I would like to present a metaphor that seems to sum up the situation as it exists today: When it comes to the relation of academic activity as it reveals itself through publications and the evaluation of these publications, consider a room filled with sentient molecules in which a thermometer is introduced. These molecular life forms can basically act in two ways: they can ignore the thermometer and try to find a way to heat up the room, or they can focus solely on the thermometer and ignore the room.

By focussing too much on 'measurable publications' a lot of disciplines are effectively neglecting the room and with this the very reason for their existence, i.e. the development of knowledge. The key to really kindling scientific activity lies in an active and productive community of researchers, sharing their work and interacting with each other with as little limitations as is possible given the technologies of the time we live in. ${ }^{21}$

\section{Bibliography}

Akker, Wiljan 2016: Yes We Should. Research Assessment in the Humanities. In: Michael Ochsner, Sven E. Hug, Hans-Dieter Daniel (eds.) Research Assessment in the Humanities. Towards Criteria and Procedures (Springer), pp. 23-29.

Atanassova, Iana; Bertin, Marc; Mayr, Philipp 2015: Mining Scientific Papers for Bibliometrics: a (very) Brief Survey of Methods and Tools. 15th International Conference on Scientometrics and Informetrics (ISSI). Available online: https://arxiv.org/ftp/arxiv/papers/1505/1505.01393.pdf.

${ }^{20} \mathrm{Cf}$. https://www.pdcnet.org/idphil/International-Directory-of-Philosophy.

${ }^{21}$ Further reading: Akker 2016; Atanassova, Bertin, Mayr 2015; Briggle, Frodeman, Holbrook 2015; Castro-Martínez 2014; Cohen 2016; Dubucs 2009; Niyazov et al. 2016; Olmos-Peñuela, Benneworth, Parks 2002; Rentier 2016; Sismondo 2016; Zic Fuchs 2014. 
Bohlin, Ingemar 2004: Communication Regimes in Competition: The Current Transition in Scholarly Communication Seen through the Lens of the Sociology of Technology. Social Studies of Science 34(3), pp. 365-391. Available online: https://www.researchgate.net/profile/Ingemar Bohlin/publication/238432379 Communication Regimes in Competition The Current Transition in Scholarly Communication Seen through the Lens of the Sociology of Technology/links/547071800cf216f8cfa9f636/ Communication-Regimes-in-Competition-The-Current-Transition-in-Scholarly-Communication-Seen-through-the-Lens-of-the-Sociology-of-Technology.pdf.

Briggle, Adam; Frodeman, Robert; Holbrook, Britt 2015: The Impact of Philosophy and the Philosophy of Impact: A guide to charting more diffuse influences across time. Impact of Social Sciences. LSE impact blog. Available online: http://blogs.lse.ac.uk/impactofsocialsciences/2015/05/26/the-impact-of-philosophy-and-the-philosophy-of-impact/.

Cohen, Philipp 2016: Developing SocArXiv - a new open archive of the social sciences to challenge the outdated journal system. LSE impact blog. Available online: http://blogs.lse.ac.uk/impactofsocialsciences/2016/07/11/developing-socarxiv-an-open-archive-of-the-social-sciences/.

Delfanti, Allesandro 2016: Beams of particles and papers. How digital preprint archives shape authorship and credit. Available online: https://arxiv.org/ pdf/1602.08539.

Dubucs, Jacques P. 2009: Humanities, Human Sciences and Digitalization. In: Changing Publication Cultures in the Humanities (27-28 November 2009). Budapest: Académie des sciences de Hongrie. Available online: http://archives.esf.org/ index.php? $\mathrm{ID}=\mathrm{tx}$ nawsecured $\& \mathrm{u}=0 \& \mathrm{~g}=0 \& \mathrm{t}=1499544558 \& \mathrm{hash}=74 \mathrm{db}-$ 983da78730e5e5ed2dce17d3ccdab9944ed9\&file=/fileadmin/be user/ research areas/HUM/Mtg documents/Restricted Pages/Changing Publication Cultures/JacquesDubucs DIGITAL $\% 20$ HUMANITIES $\% 20 \% 28 \mathrm{Buda}-$ pest $\% 20$ nov $\% 2009 \% 29$.pdf.

Gunnarsdóttir, Kristrún 2005: Scientific Journal Publications: On the Role of Electronic Preprint Exchange in the Distribution of Scientific Literature. Social Studies of Science 35(4), pp. 549-579. Stable URL: http://www.jstor.org/stable/25046659.

Hammarfelt, Björn 2014: Using altmetrics for assessing research impact in the humanities. Scientometrics 101(2), pp. 1419-1430. Available online: https://doi. org/10.1007/s11192-014-1261-3 (purchase PDF).

Larivière, Vincent; Haustein, Stefanie; Mongeon, Philippe 2015: The Oligopoly of Academic Publishers in the Digital Era. Plos One 10(6), e0127502. Available online: http://journals.plos.org/plosone/article?id=10.1371/journal.pone.0127502. 


\section{Steven Laporte}

\section{Preprint for the humanities - fiction or a real possibility?}

Linmans, A. J. M. 2010: Why with bibliometrics the Humanities does not need to be the weakest link. Indicators for research evaluation based on citations, library holdings, and productivity measures. Scientometrics 83(2), pp. 337-354. Available online: https://doi.org/10.1007/s11192-009-0088-9 (purchase PDF).

Luther, Judy 2017: The Stars Are Aligning for Preprints. Available online: https:// scholarlykitchen.sspnet.org/2017/04/18/stars-aligning-preprints/?informz=1.

Moed, Henk F. 2005: Citation analysis in research evaluation. "Information Science and Knowledge Management" 9. Dordrecht, The Netherlands: Springer.

Niyazov, Y.; Vogel, C.; Price, R.; Lund, B.; Judd, D.; Akil, A.; Mortonson, M.; Schwartzman, J.; Shron, M. 2016: Open access meets discoverability: Citations to articles posted to Academia.edu. PLOS ONE, 11(2), e0148257. Available online: https://doi.org/10.1371/journal.pone.0148257; http://journals.plos. org/plosone/article?id=10.1371/journal.pone.0148257.

Olmos-Peñuela, Julia’ Benneworth, Paul; Castro-Martínez, Elena 2014: Are 'STEM from Mars and SSH from Venus'?: Challenging disciplinary stereotypes of research's social value. Science and Public Policy 41(3), pp. 384-400. Available online: https://doi.org/10.1093/scipol/sct071 (purchase PDF).

Parks, Robert P. 2002: The Faustian grip of academic publishing. Journal of Economic Methodolog 9(3), pp. 317-335. Available online: https://doi.org/10.1080/ 1350178022000015122 (purchase PDF).

Rentier, Bernard 2016: Open science: a revolution in sight? Interlending \& Document Supply 44(4). Available online: http://orbi.ulg.ac.be/bitstream/2268/198865/1/ Open $\% 20$ Science $\% 20 \mathrm{a} \% 20$ revolution $\% 20$ in $\% 20$ sight .pdf.

Reyes-Galindo, Luis Ignacio 2016: Automating the Horae: Boundary-work in the age of computers. Social Studies of Science 3, pp. 107-111. Available online: https://arxiv.org/pdf/1603.03824.

Sismondo, Sergio 2016: Sorting on arXiv: Introduction to an ad hoc section. Social Studies of Science 46(4), pp. 583-585. Available online: http://journals.sagepub.com/doi/pdf/10.1177/0306312716661429.

Suber, Peter 2005: Promoting Open Access in the Humanities. Syllecta Classica 16, pp. 231-246. Available online: https://dash.harvard.edu/bitstream/handle/1/4729720/suber promoting.htm? sequence=1.

Van Leeuwen, Thed 2013: Bibliometric research evaluations, Web of Science and the Social Sciences and Humanities: a problematic relationship? Bibliometrie Praxis und Forschung 2, pp. 8-1-18. Available online: http://www.bibliometrie-pf. de/article/download/173/218.

Zic Fuchs, Milena 2014: Bibliometrics: use and abuse in the humanities. In: Bibliometrics: Use and Abuse in the Review of Research Performance ("Wenner-Gren International Series” 87; Portland Press Limited), pp. 107-116. Available online: http:// www.portlandpress.com/pp/books/online/wg87/087/0107/0870107.pdf. 